\title{
Bases socio-metodológicas para el Análisis de Redes Sociales, ARS
}

\author{
Carlos lozares Colina \\ Universidad Autónoma de Barcelona \\ Carlos.Lozares@uab.es
}

Recepción: septiembre 2005

Aceptación: noviembre 2005

\section{INTRODUCCIÓN}

El ARS se presenta, a veces, como una caja de herramientas de naturaleza técnico- formal y/o gráfica en la búsqueda pragmatista y eficaz de resultados sin que se dé una reflexión suficiente sobre las condiciones y situaciones de recogida de información o sobre la naturaleza de los datos y su contextualización o sobre las dimensiones cognitivas, fácticas, dinámicas, simbólicas etc. que supone la relación social o sobre los campos en los que se insertan dichas relaciones. De lo que se trata en este artículo es precisamente de no desvincular las cuatro palabras clave que componen y han de estar presentes armónicamente, en dosis ponderadas, en el ARS: la Teoría/Conceptos, Análisis/Dato, Redes/Interacción y su pertinencia Social. Es decir, lo más alejado del uso del ARS como una máquina neutra, rápida y utilitaria para obtener y reticular datos olvidando la naturaleza y contenidos de lo que se elabora, las condiciones sociales de la gestación de las relaciones o redes sociales y las implicaciones metodológicas de la recogida de información y del análisis de datos ${ }^{1}$.

El ARS viene ya marcado de salida, como su nombre indica, más como un método de análisis que como una teoría sociológica quizás por la dificultad de encaje que encuentra en las teorías clásicas o por el áurea interdisciplinar que le acompaña. Por otro lado, aunque el ARS posee una indudable tradición holística, dicho holismo suele referirse exclusivamente a los elementos y relaciones que configuran su red y no a los contextos o sistemas en los que se inscribe. El ARS es considerado microsocial dada su dedicación relativamente mayoritaria a los pequeños entornos, grupos y/o poblaciones reducidos pero también macrosocial

1 Para aspectos generales del ARS, ver Borgatti y Foster 2003, Carrington, Scoth y Wasserman 2005, Granovetter 1973, Lemieux 1999, Lozares 1996, 2003b, Cross y Parker 2004, Mercklé 2004, Molina 2001, Knoke y Kuklinski 1982, Requena 1989, Scott 1991, Wasserman y Faust 1994, Wellman 1983, Wellman y Berkowitz 1988, http://www.redes-sociales.net, http://revista-redes.rediris.es. 
pues trata con entidades sociales de más envergadura. El ARS no es de por sí ni exclusivamente macrosocial ni microsocial pudiendo ser también mesosocial, ni es holista ni individualista/atomista y/o reduccionista siendo como es relacionista. El relacionismo aparece como una aproximación teórica pertinente para enmarcar el ARS al considerar los fenómenos/hechos sociales como relaciones entre sujetos o entidades sociales y postulando que lo social no se constituye, en primera instancia, a través de categorías sociales o atributos de los individuos o agentes (variables) sino por los vínculos entre actores, incluso no estando directamente relacionados ${ }^{2}$. Siguiendo esta lógica los agentes adquieren su identidad social germinal, y por tanto su posición y estatus, a partir de las interacciones y relaciones que constituyen, por otro lado, su contexto de producción más inmediato. A su vez, dichas posiciones llegan a ser recursos para nuevas interacciones y relaciones. En la perspectiva del ARS, la relación se supone ontológica y conceptualmente anterior a las categorías (atributos y variables) pues se generan a partir de relaciones de equivalencia; por tanto, son las categorías las que han de ser explicadas por las relaciones. En este sentido se puede hablar de una aproximación diferente a la que ha estado tan omnipresente en sociología como es la explicación de los comportamientos, creencias, hábitos, hechos sociales, estructura, etc. por factores expresados como variables categoriales y/o atributivas (STRUCTURE, Versión 4.2, 1991). El examen de la posición teórica y epistemológica del ARS no es el objetivo de este artículo pero muchas reflexiones que en él se vierten pueden contribuir indirectamente a ello.

\section{LA INTERACCIÓN SOCIAL, IS, EL HECHO SOCIAL, HS, LAS RELACIONES, REDES SOCIALES Y EL ARS}

En el origen de todo fenómeno/hecho social se encuentra la Interacción Social, IS, y su correlato inmediato, el Hecho Social, HS. Ambos no pueden considerarse independientemente sino constituidos en una entidad dual, ontológica y socialmente inseparable. Así, el doblete, Interacción-Hecho Social, $\left(\mathrm{I}^{\wedge} \mathrm{H}\right) \mathrm{S}^{3}$, es el núcleo primigenio e irreducible de lo social y, por tanto, su unidad de referencia más elemental. Del doblete $\left(\mathrm{I}^{\wedge} \mathrm{H}\right) \mathrm{S}$ proviene la estática y dinámica social, emergiendo así los agentes sociales, recursos y estrategias sociales así como la estructura social. Se define aquí el doblete $\left(\mathrm{I}^{\wedge} \mathrm{H}\right) \mathrm{S}$ como un conjunto de prácticas objetivas y cognitivas de intercambio, Interacciones Sociales, entre agentes,

2 (Para el Relacionismo ver Bajoit 1992, Cross y Parker 2004, Emirbayer 1997, Galaskiewicz y Wasserman 1993, Granovetter 1973, Hollis 1998, Knoke y Kuklinski 1982, Ritzer 2000, Ritzer y Gindoff 1992, Salvador Juan 1995, Scott 1998, STRUCTURE Versión 4.2. 1991, Verschuren Piet 2001, Wellman 1983, Wellman y Berkowitz (Eds) 1988 )

${ }_{3}$ (Para la Interacción Social ver Blumer 1969, Bourdieu 1977, Collins 1987, Crespi 1989, Edmond y Dominique 1992, Garfinkel 1967, Giddens 1984, Goffman 1967, 1971, Habermas 1984, Homans 1974, Hymes y Gumperz 1972, Lamo de Espinosa 1990, Layder 1981, Lofland 1978, Mead 1934, 1938, Schüiz y Luckman 1973, Tumer 1988, Vygotsky 1978, Waters 1994)

EMPIRIA. Revista de Metodología de Ciencias Sociales. N. ${ }^{\circ}$ 10, julio-diciembre, 2005, pp. 9-35. 
personas y/o artefactos, que ponen en juego sus recursos con la intención o propósito, manifiesto o no, de captar y/o apropiarse del producto emergente, $\mathrm{He}$ cho Social, que se genera en el propio desarrollo de la interacción, (Gráfico 1).

Desde esta identificación elemental se puede ya percibir la presencia y composición de los diferentes elementos integrantes de la dualidad $\left(\mathrm{I}^{\wedge} \mathrm{H}\right) \mathrm{S}$ : (i) Los agentes que modifican (o se resisten a la modificación de) la realidad objeto del proceso a partir de la interacción. (ii) Los recursos a disposición de los agentes y que, contemplados desde la IS como centro de gravedad, definen a los mismos agentes. (iii) Las prácticas de interacción de los agentes, más o menos informados, y sus estrategias que se han de entender como la aplicación entre los medios o recursos de los agentes puestos en juego y la representación anticipada de los resultados y virtualmente apropiables por los agentes. Así pues, las prácticas de intercambio o IS se componen como también el HS, dual pero inseparablemente, de un plano de objetivación (visibilidad, funcionalidad y/o uso de la interacción) y de otro cognitivo (intencionalidad, propósito, representación, etc., ambos de los agentes que intervienen). (iv) La dinámica propia del proceso que modifica el objeto de su acción a partir de una «cola de entrada» y de su desarrollo y que obtiene un resultado o producto no equivalente necesariamente a la imagen o representación previas de los agentes sobre dichos resultados. (v) La distribución y apropiación mutua, equitativa o no, de la plusvalía o producto generado por el proceso de interacción que está al origen del vínculo o red entre los agentes. (vi) Las determinaciones o condiciones, más o menos fuertes, que favorecen o constriñen el proceso en un sentido u otro (a veces incorporadas a los recursos de los agentes, a veces como reales sujetos) y que tienen su origen en los contextos y campos con los que la interacción interfiere y que, además, contribuye a estructurar.

Considerando la compra en una pescadería de un mercado municipal observamos: (i) Los agentes marcados como compradorla y pescateralo y otros agentes expectantes a la espera de su turno; (ii) con unos recursos propios que se intercambiarán en el proceso; (iii) y unas prácticas de intercambio con diferentes canales: conversación, gestual o corporal, manual, etc. y de diversa naturaleza, no sólo del campo mercantil, sino de intercambios emocionales, de cortesía, de amistad, (todos ellos cotidianos en la pescadería de barrio), de recetas, de recuerdos, etc.; (iv) la interacción lleva su curso de desarrollo: "cola de entrada», me «toca la vez» y saludo; elección, desguace, limpieza, corte, intercambios verbales ad hoc, pesada; desenlace en el cobro, toma en mano del producto y despedida; ( $v$ ) se da una distribución de las plusvalías, equitativa o no, y unos vínculos o relaciones que permanecen, algunos hegemónicos según la naturaleza del intercambio (pe. el ticket de la compra), pero también otros menos formales o no mercantiles, conocimiento, afecto, simpatia... (vi) todo ello se lleva a cabo, primero, en un campo socioeconómico como es el mercantil, propio a un mercado municipal, pero con una forma específica de combinarse con las lógicas de otros campos cotidianos, conocimiento y amistad de la gente, etc. y, segundo, en unos entornos cercanos como es el de la parada concreta y la clientela o en el marco inmedia- 
to del conjunto de las pescaderías del mercado o el mismo mercado municipal, y en otros contextos más genéricos como la gerencia del municipio, mercabarna...; de todos ellos se pueden poner en evidencia sus agentes correspondientes, sus recursos, sus momentos y formas de intervención y sus resultados.

Captar y analizar uno de los dos componentes, IS o HS, del doblete $\left(\mathrm{I}^{\wedge} \mathrm{H}\right) \mathrm{S}$ como exclusivo objeto de estudio es aceptar de entrada un sesgo ontológico y analítico. Pero, por otro lado, poner en juego la dualidad y la necesaria vinculación entre sus elementos se presenta complicado. La toma en cuenta de la totalidad que constituye una Red Social (acontecimiento en situación, entorno, proceso y resultado así como sus marcos y contextos), es decir, el análisis de la dualidad que contiene doblete $\left(\mathrm{I}^{\wedge} \mathrm{H}\right) \mathrm{S}$ así cómo las condiciones de su gestación, dinámica, contextos y resultado, y no sólo la objetivación de un vínculo, es un reto metodológico y una apuesta compleja para el ARS.

\subsection{El dipolo IS y HS, $\left(I^{\wedge} H\right) S$, como primera dualidad inherente en el ARS}

La producción de un resultado o HS es inseparable de la IS de la que proviene; a su vez, los HS son también parte de los recursos y configuran la estructura social interviniendo y condicionando las IS; esto es, IS y HS se generan y condicionan mutuamente en el dipolo dual $\left(\mathrm{I}^{\wedge} \mathrm{H}\right) \mathrm{S}$ : la IS se refiere a su fase dinámica, transicional o cambiante del proceso (aunque no se entra aquí en cómo opera tal dinámica) y el HS se refiere a la fase producto, estado o resultado del dipolo $\left(\mathrm{I}^{\wedge} \mathrm{H}\right) \mathrm{S}$. Como bien se sabe, la centralidad o enfoque exclusivo, teórico y/o metodológico, en uno de los polos excluyendo el otro ha establecido (y estado al origen de), sobre todo en sociología, divisiones irreconciliables entre escuelas teóricas y metodológicas, (Gráfico 1).

El tomar el dipolo $\left(\mathrm{I}^{\wedge} \mathrm{H}\right) \mathrm{S}$ en su relación dinámica y estructural, como entidad social y metodológica irreductibles de estudio, no algo evidente y ausente de problemas tanto para su observación o recogida de datos como para su análisis. Parece como si, análogamente a lo que sucede en física, se diera entre ambos componentes o fases, IS y HS y su vinculación, un cierto principio de incertidumbre ad hoc por el que «cuanto más se focalice o precise la recogida de la información y el análisis sobre la dinámica de la IS, más desenfocado o impreciso queda el HS en tanto que estado o resultado, y a la inversa». Fijados directamente sobre el resultado o HS actual no es evidente que se tenga acceso, también directo e instantáneo, a las condiciones de su producción, esto es, a la IS, quedando, en consecuencia, imprecisas y no válidas facialmente, aunque de alguna manera pudieran ser cercadas a partir de la memoria de los informantes pe. mediando encuesta, entrevista o archivo o bien que del HS se pudiera inferir algo sobre la IS y su dinámica. En el caso inverso, el de la recogida de información 


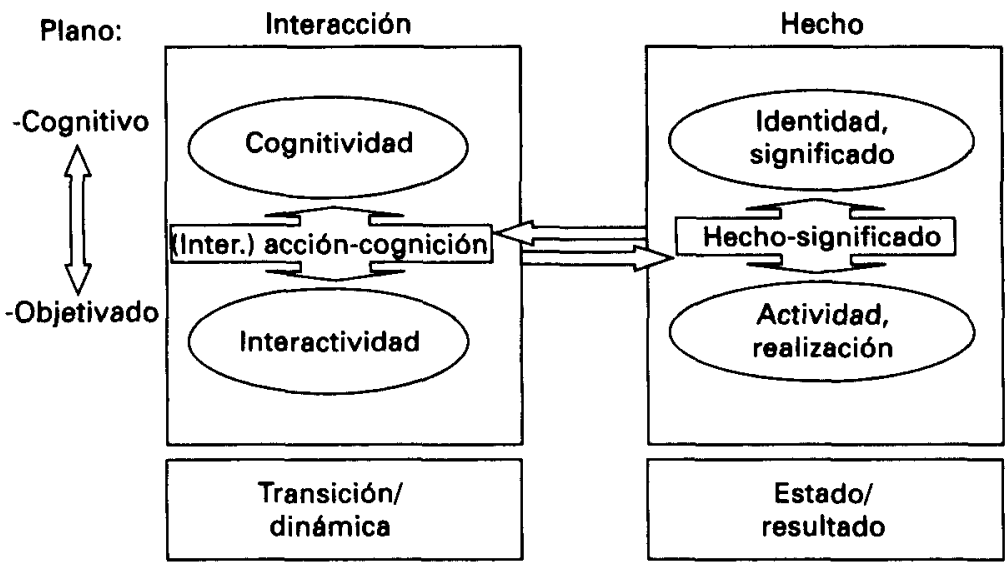

Gráfico 1.

sobre IS actuales (por métodos intensivos, naturalistas, observacionales, situacionales y en general etnográficos) se puede conseguir un elevado grado de verosimilitud y precisión actual de las IS pero dejando borrosos o sólo inferibles los resultados o HS porque sencillamente se difuminan en su extensión social y/o porque se eslabonan en interacciones sucesivas difícilmente perceptibles y predecibles en su futurible.

La información que se recoge y maneja en la metodología de la ARS son relaciones, vínculos o conexiones, pero, normalmente, en tanto que HS o resultado estabilizado que es más accesible. Desde luego, no se acostumbra tanto a recoger las IS ${ }^{4}$ en vivo, que también son Redes Sociales como realidad dinámica. $\mathrm{La}$ información reticular obtenida por encuesta o entrevista, procedimientos corrientes, no es la IS como relación original o primigenia que se busca y recoge sino una objetivación de la misma en tanto que hecho en el stock de la memoria de los agentes entrevistados o encuestados y que se actualiza mediando otra interacción diferente como es la que se da en toda encuesta o entrevista. Algo así como si pasara por un cedazo de doble fondo u objetivación, suponiendo además que «sin romperse ni mancharse». Todo ello puede alejar las RS de las condiciones y situación de las IS genuinas en que se generan. Son varios los caminos o alternativas: primero, el sesgado, tratando separadamente cada uno de los polos, o sólo uno de los dos, IS o HS; segundo, el de la lógica de la teoría de la complejidad, considerando la RS como una realidad emergente como es el

${ }^{4}$ Este polo es de más difícil acceso: sus cambios instantáneos y el hecho de que las metodologías optimas para ello, como las etnográficas e intensivas y/u observacionales, tienen su grado de dificultad de accesibilidad y puesta a punto. La dificultad es mayor si se pretende entrar en los mundos cognitivos internos a los agentes como parte decisiva de la interacción... 
la dualidad $\left(\mathrm{I}^{\wedge} \mathrm{H}\right) \mathrm{S}$ pero con el riesgo de una ontología por descubrir, de una teoría incipiente y con una metodología a explorar; tercero, y mientras tanto, un cierto apaño pragmático y honesto científicamente, es decir, bizqueando a los dos lados pero de tal forma que aunque se enfoque más uno de ellos no se deje al otro de lado. Hay dos posibles salidas razonables a esta alternativa para aliviar posibles defraudes y sobre todo para no romper «lo que la realidad ha unido»: en primer lugar, que elegido un objeto directo de estudio, sea la IS o el HS, se acepten determinados supuestos sobre la naturaleza e influencia del «dejado de lado»; en segundo lugar, que al menos se aborden también algunas de las características o propiedades generales de la dualidad $\left(\mathrm{I}^{\wedge} \mathrm{H}\right) \mathrm{S}$ que no sean exclusivamente reducibles a una de las partes.

\subsection{El dipolo de las representaciones: (Interno/Cognición) v. (Externo/Objetivación) en el $\left(I^{\wedge} \mathbf{H}\right) \mathrm{S}$ como segunda dualidad inherente al ARS}

Otra de las dualidades de particular incidencia en sociología es la que opone y vincula el plano cognitivo al objetivo dentro del doblete $\left(\mathbf{I}^{\wedge} \mathrm{H}\right) \mathrm{S}$. Esta dualidad también atraviesa la RS y el ARS. Los aspectos o dimensiones internos o cognitivos de los agentes o instrumentos están vinculados a los externos u objetivos tanto en la IS como en los HS; es más, ambas dimensiones se generan mutuamente en situaciones pragmáticas de tal manera que sólo el soporte en el que se expresan y la disección analítica permiten su distinción. Tanto en la IS como en el HS todo componente de actividad, acción, comportamiento etc. que modifica objetivamente (o se resiste a la modificación de) una realidad social se corresponde con (y genera) procesos cognitivos (intención o proyecto, representación, memoria, decisión previa, intra o post-interacción) y viceversa, (Gráfico 1).

La fase de dinámica, transicional o de cambio, es decir, la de la IS, vista como dualidad dipolar Cognición-Objetivación, la denomino aquí (1) (Inter)acción-Cognición; a la fase de realización y resultado, esto es, del HS visto como dualidad o dipolo Cognición-Objetividad, (2) Hecho-Significado.

En la parte dinámica, (1) de (Inter)acción-Cognición de la IS, se establece la distinción entre, de un lado, la Interactividad que constituye el componente objetivo y, de otro, la Cognitividad que es el componente subjetivo, esto es, el conjunto de representaciones, memoria, conocimientos semánticos, narrativos, situacionales y proyectos en proceso dinámico internos a los agentes en la IS. Ambos componentes que, además se autogeneran mutuamente (sólo cambian de su externalidad a su internalidad y viceversa), están en la base misma del dinamismo de la IS hasta su equilibrio (quizás relativo) que supone el HS, estado o resultado.

En la parte estable, (1) de Hecho-Significado del HS se establece la distinción entre, de un lado, la Realización o Actividad que constituye su vertiente objetivada, esto es, el resultado producido, manifiesto o externalizable - aunque 
sea simbólico- y, de otro, el Significado o Identidad que es su componente subjetivo, o cognitivo interno, en el sentido de que, aunque atribuido al bien producido y constituyendo a su identidad, es una realidad conceptual interna a los agentes. No se ha de olvidar que el Hecho-Significado, primero, es un Hecho, esto es, algo constituido o en fase de estado pero también es una representación internalizada por el agente; segundo, que el Significado lo es a partir de las condiciones de su producción, no de la nueva identidad que el HS pudiera adquirir para una nueva IS pe. la del investigador con su objeto de estudio.

Como síntesis, y vinculando lo precedente a Teorías como las de la Acción, de la Actividad o Conocimiento Situado y del Conocimiento Socialmente Distribuido ${ }^{5}$, mi punto de vista es que, primero, todo conocimiento tiene su raíz o se genera en una IS en situación, y viceversa. Segundo, ello conforma un sistema (Inter)acción-Cognición que puede interpretarse como una representación distribuida y transformable en el proceso de interacción y conformada al final en su fase de estado como Hecho-Significado. Tercero, dicha representación tiene un componente interno en los agentes, su significado, y otro externo que no es más que la externalidad de la representación. Las representaciones no son algo exclusivamente dentro del agente o internas, sino que pueden ser externas a los agentes, pe. una página escrita, un mesa llena de utensilios son representaciones externas de y para el conocimiento del agente.

¿Qué tiene que ver todo esto con el ARS?. Sea el caso de un banquete de boda «por la iglesia» como situación de interacción y hecho y consideremos el fenómeno en tanto que Relaciones Sociales, siendo conscientes de que no todo lo que sucede en dicha situación es vínculo reticular ${ }^{\circ}$.

Los dos componentes de la dualidad dinámica del (INH)S, es decir, de la IS, la (1) (Inter)acción-Cognición son:

El primero, que hemos denominado Interactividad consiste del conjunto (o alguna) de las interacciones manifiestas y visibilizadas que se dan al inicio y a lo largo del banquete entre los «actores»?. Asi pues hay, en primer lugar, una reticulación inicial o cola de entrada que consiste en la posición relativa y reticular de la colocación inicial «estar cerca de» en la mesa y/o tarjera que

${ }^{5}$ Las perspectivas de las ciencias cognitivas actuales superan el cognitivismo clásico de Descartes, (Clark 1996). Las nuevas concepciones mantienen, contra el cartesianismo, una continuidad interactiva y evolucionaria entre cuerpo y mente: la cognición es mucho más que las representaciones internas mentales (Norman 1993, Zhang y Norman 1994) como es el caso del Conocimiento Situado o de la Cognición Socialmente Distribuida (Hutchins 1995 a.b., Lozares 2000, 2001, Kirsh 2001, Cicourel 1994, 2003, Hutchins y Klausen 1996, Pea 1993).

6 Los «reticulistas» corremos el riesgo de pensar que la única realidad social pertinente son las relaciones. Es evidente que la especialización llama a una cierta exclusividad autista y con ello a sesgos posibles.

${ }_{7}$ Se puede tomar, para mayor sencillez, actores un tanto agregados, como (i) los novios, (ii) los padres/padrinos/as por parte del novio, (iii) por parte de la novia, (iv) los invitados familiares por parte de novio, (v) por parte de novia, (vi) los amigos/as y otros/as invitados/as por parte del novio, (vii) de la novia; (viii) el cura, (ix) los camareros, (x) el jefe de camareros, (xi) músicos, (xii) fotógrafo, (xiii) niños... 
es una representación externa de la red en el convite y, luego, la red dinámica que "acumula" ${ }^{8}$ el conjunto de las interacciones mutuas inacabadas, inconclusas consideradas a lo largo del convite pero activadas entre los actores..

El segundo que hemos llamado Cognitividad consiste, en primer lugar y como "cola de entrada", de las imágenes mentales o representaciones internas que los actores tienen de las relaciones mutuas que provienen de su biográfica o simplemente imaginada o inferida y, en segundo lugar, de la imagen relacional evolutiva y dinámica que se va activando en el convite en vistas a la Interactividad. Estas imágenes son decisivas en el desarrollo de la Interactividad del banquete ya que son parte de los recursos y procesos intencionales para las sucesivas interacciones.

Los dos componentes de la dualidad o sea el producto, resultado o fase de estado del (INH)S, esto es, el (2) Hecho-Significado, son:

El primero, que hemos denominado Realización o Actividad consiste, como parte objetiva y externalizable, de los ritos o actividades en tanto que resultados como pe. las redes creadas en la despedida o antes. Pueden manifestarse por muchos canales de expresión, contenidos y grados de intensidad ${ }^{9}$.

El segundo, que hemos denominado Significado o Identidad consiste, como componente subjetivo o interno, del sentido reticular que tiene cada uno de los actores-comensales de su ego-reticular y del conjunto de las relaciones que "han quedado» a partir del convite y la imagen reticular que como colectivo tienen los agentes en tanto que conocimiento socialmente distribuido.

La dualidad presentada entre Conocimiento, o internalidad cognitiva de los procesos sociales, versus Objetivación de la acción, o representaciones externas, proporciona una nueva disyuntiva y riesgo de corte transversal no sólo dentro del $\left(\mathrm{I}^{\wedge} \mathrm{H}\right) \mathrm{S}$ y ARS sino que, más extensamente, es la que se da entre la realidad social concebida como construcción simbólica, socialmente existente sólo en cuanto que es representada o es objeto de procesos intencionales, de un lado, y, de otro, la realidad social en cuanto objetivación externamente observable. Esta disyunción ha sido también fuente permanente de posiciones y divisiones encontradas, concretamente en sociología, entre corrientes teóricas constructivistas, fenomenológicas, hermenéuticas, de un lado, y positivistas o neopositivistas, de otro, y entre metodologías de cariz cualitativo frente a las cuantitativistas (Lozares, Martín y López 1998). Esta disyuntiva teórica y metodológica puede multiplicarse por dos, una por cada vertiente del $\left(\mathrm{I}^{\wedge} \mathrm{H}\right) \mathrm{S}$ : en el lado dinámico de la IS o (Inter)actvidad-Cognición, entre la Interactividad y la Cognitividad, y,

${ }^{8}$ Se pueden desagregar por canales, (gestos y miradas detenidas, conversaciones y en temporalidades menores marcadas como fases) y suponer pe. que basta conque una persona de uno de dichos «actores» establezca una relación con otra de otro 'actor' sea suficiente como para hablar de vínculo entre «actores».

${ }^{9}$ Canales pueden ser el habla, la tarjeta intercambiada, un escrito en la servilleta, etc. o el gesto, la mirada, el abrazo, etc.; como contenidos, el conocimiento mutuo, el económico, el afectivo, la visita concertada, etc.; como intensidad pe. del saludo de despedida: el formal, con sonrisa, abrazo, beso, etc, con o sin pase del $n .^{\circ}$ de teléfono, de la dirección, del correo... 
en el lado del HS o Hecho-Significado entre la Realización o Actividad y el Significado o Identidad.

Nuestro punto de partida es que, aunque se traten analíticamente diferenciadas, la internalidad del conocimiento y la externalidad de la acción, se ha de encontrar la metodología y métodos adecuados para que, de alguna manera, no se desvincule lo que ontológicamente y por generación recíproca está vinculado. Esta problemática metodológica aparece por ejemplo en el ARS en la distinción y necesaria conjunción entre las RS cognitivas propias a la mente de los agentes y las objetivadas externamente.

El sesgo que puede darse en el ARS, vinculado a los métodos de entrevista o encuesta y que comparte con otras aproximaciones sociológicas, consiste en interpretar como absolutamente objetivadas, como representaciones externas fidedignas, las respuestas sobre RS que no dejan de ser una construcción subjetiva interna del entrevistado/encuestado sobre hechos o situaciones reales a los que el investigador no tiene acceso directo. Los métodos, y la manera de aplicarlos en el ARS, pueden amortiguar, en parte, el efecto de dicha dicotomía analítica: la recogida de información en RS acostumbra a hacerse en una situación, actual y/o narrativa o supuesta, relativamente más conocida y definida por los agentes que la genérica y asituacional de un muestreo aleatorio; en RS se exigen respuestas recíprocas con lo que, de alguna manera, se con-validan respuestas mutuas y se contrasta deseos y/o cognición con realidad; se manejan grupos pequeños facilitando la triangulación; y, si se acompaña de metodologías etnográficas, es más fácil inferir aspectos intencionales, representaciones...

En el sentido de no desdoblar o dicotomizar la vinculación Cognición-Objetivación es de interés que las preguntas generatrices sobre un determinado objeto o contenido reticular tengan la doble cara, la cognitiva y la objetivada; es decir, una pregunta generatriz que exprese la parte de la acción o hecho objetivado o de facto y, otra, que se refiera a los estados o procesos cognitivos, sean intencionales, representaciones, inteligencia emocional, desideratas, etc. correspondientes. Adicional, pero imprescindiblemente, se han avanzar hipótesis o en todo caso supuestos (o se ha de tener un grado de conocimiento) sobre las vinculaciones e inter-relaciones que mantienen ambos planos (el del conocimiento y el de la facticidad) y sobre cómo se autogeneran pragmática y socialmente.

\section{EL ENTORNO Y EL PROCESO SOCIAL, COMO UNIDAD DE ANÁLISIS, LAS RS Y EL ARS.}

En cualquier proceso real, sea de vida cotidiana o de trabajo, los $\left(\mathrm{I}^{\wedge} \mathrm{H}\right) \mathrm{S}$ se multiplican, primero, «entornándose» con otros y con los contextos de manera envolvente desde un centro a sus periferias contextuales y campales, $y$;' segundo, articulándose en el tiempo con otros $\left(I^{\wedge} \mathrm{H}\right) \mathrm{S}$. Pero, por otra parte, los objetos de estudio tienen un foco que es su unidad de referencia de análisis y unos contextos y, por tanto, un grado de separación entre ambos, aunque las barreras sean 
fluidas y/o borrosas. Por ello, es decisivo identificar en los objetos de estudio los contenidos más adecuados como foco y como contextos. Precisamente lo que denominaré Entorno-Proceso, se entenderá social en lo sucesivo, será considerado como unidad de análisis u objeto o foco de estudio.

¿Tomamos, para un ARS, todo el convite de una boda como unidad de análisis u objeto de estudio, o sólo uno de sus momentos estelares como es el de la «entrada, descubrimiento, apoteosis, corte y distribución» de la tarta (lo que denominamos a continuación Entorno-Proceso) o sólo el beso nupcial (sería equivalente a un solo $\left(I^{\wedge} \mathrm{H}\right) \mathrm{S}$ ) o el del baile con sus emparejamientos y músicos, (otro Entorno-Proceso): quién baila con quién, etc.? ¿Por qué no vincular también el convite, temporal y linealmente, con la boda en la iglesia como una sola unidad de análisis reticular?, ¿por qué no con la sesión de fotos, "quién se fotografía con quién y/o al lado de quién o a qué distancia está en la foto", o "quién habla con quién en el aperitivo"? ¿Qué es lo más informativo? ¿Cómo articularlo todo, reticular y temporalmente?

También es decisiva la arquitectura social para delimitar la expansión de los $(I N H) S$, ¿cuál es la unidad de análisis y sus envolventes?: ¿el convite y lo que sucede en la sala, o más ampliamente el ensamblaje relacional comedorcocina, o el restaurante en su totalidad donde al mismo tiempo se celebran varias bodas, o introducimos también todos los actores-instituciones que han intervenido en el acontecimiento como fotografía, imprenta, sastrería-tienda, iglesia, juzgado, y ... la banca con su crédito?

Teniendo en cuenta las dimensiones de expansión centro-periferia y la sucesión y articulación de los $\left(\mathrm{I}^{\wedge} \mathrm{H}\right) \mathrm{S}$ defino dos conceptos que vinculados proporcionan la unidad adecuada de referencia sustantiva y de análisis: en la dimensión de su expansión centro-periferia, hablaré de Entorno Social, y en la temporal, de Proceso Social. Ambos constituyen una entidad sustantiva y metodológica que denomino Entorno-Proceso, Una distinción imposible entre Entorno y Proceso nos permitirá comprender mejor su contenido.

El Entorno Social situacional lo considero como un conjunto o totalidad de dobletes $\left(\mathrm{I}^{\wedge} \mathrm{H}\right) \mathrm{S}$ que se dan en una fase de transición, vinculados y articulados entre sí con los correspondientes agentes personales o instrumentales correspondientes y sus recursos que (pertenecen a) e intervienen y/o se generan en la situación inmediata, las funciones instrumentales y el conjunto de representaciones asociadas, así como los productos en transformación o transformados en tanto que resultado. Así pues, se trata de un sistema interactivo, funcional, cognitivo y social en un momento del proceso general. Esta definición equivale a lo que Kirsh (2001) denomina Entorno, un «espacio-momento-contenido» donde se realizan las interacciones y se generan las dinámicas fundamentales del proceso y donde, por supuesto, se hacen más manifiestos y «a cuerpo entero» algunos de los agentes que intervienen, personas, ordenadores, comunidad de prácticas, grupo de trabajo,... El concepto de Proceso Social consiste en la toma en cuenta de la dilatación temporal y articulada de los diferentes $\left(\mathrm{I}^{\wedge} \mathrm{H}\right) \mathrm{S}$ (en el límite puede darse un solo $\left.\left(\mathrm{I}^{\wedge} \mathrm{H}\right) \mathrm{S}\right)$. Se trata de la dinámica propia y la sucesión que se 
establece a partir de un conjunto de interacciones con cierto grado de convergencia y coherencia en vistas a la obtención de un producto o resultado social. $\mathrm{Si}$ el Entorno social representa el lado de la composición de cada fase del proceso, el Proceso Social es la dinámica del cambio de fases en perspectiva temporal.

En el Entorno-Proceso se integran pues el contenido paradigmático del Entorno, como estado y elementos en presencia, y el contenido sintagmático y temporal del Proceso. Su identidad, propiedades o dimensiones y dinámicas, que lo configuran como sistema, se refieren también a la doble naturaleza de los $\left(\mathrm{I}^{\wedge} \mathrm{H}\right) \mathrm{S}$, como dinámico y estado, y como objetivación/subjetivación. El EntornoProceso pasa a ser, desde mi perspectiva, la unidad de referencia más adecuada para el análisis social. A partir del Proceso social se dan en el Entorno-Proceso, fases de transición y estado con cierta tensión o grado de equilibrio inestable hasta una situación final que marca un grado relativo de equilibrio más o menos estable. Como veremos el grado de estabilidad del Entorno-Proceso es un buen criterio para marcar sus fronteras y, por tanto, para establecerlo como unidad de análisis o foco de estudio más adecuado.

En un andén de estación y en una situación inminente de salida del tren la pregunta a un transeúnte o en información sobre la hora de salida de un tren es una IS con la ignorancia como recurso, las prisas y el nerviosismo, maleta en mano, billete en boca, amigos en despedida...La IS y la respuesta, "del andén 2», configuran entre ambos lo que he denominado (INH)S. Esta respuesta o resultado está llamando a voz en grito a ser 'cola de entrada' de otras $(I M) S$ : abrazos rápidos de despedida individual o en coro a colegas y familiares, subida el tren que arranca y luego, al final, los adioses gestuales recíprocos desde la ventanilla y andén. Este conjunto de $(\mathrm{I} / \mathrm{H}) \mathrm{S}$ articuladas sincrónica y diacrónicamente lo defino como Entorno-Proceso, y sería en mi caso tomado como la unidad de referencia más pertinente informativamente de análisis: cada uno de los (I^H)S, aunque considerados como unidades irreductibles de lo social no son la unidad más adecuada de análisis, precisamente por el grado de inestabilidad, tensión o de «inacabado» que presenta cada uno. El resultado «final», es decir, "cuando un amigo se va...» y el tren parte con un 'adiós en mano' saliendo de la ventanilla, tiene un mayor grado de estabilidad que la respuesta "del andén 2 "dada la situación global y el seguimiento temporal de lo que sucede.

Veamos más detenidamente algunos aspectos decisivos de los Entorno-Procesos.

Primero, el Entorno-Proceso está formado por conjuntos de interacciones en módulos conexionados cuya articulación y arquitectura temporal puede ser variada en su composición: en línea, consecutiva o diacrónica; en paralelo, superpuesta y/o en simultáneo; en bucles retroactivos, etc. En el Gráfico 2, las dos primeras líneas son paralelas (el proceso se compone de una bifurcación de la cadena de interacciones) y proceden en simultáneo; parte de la segunda y la tercera forman un bucle retroactivo, (elemento importante para la complejidad). Los procesos de trabajo suelen presentar éstas y otras complejidades. 


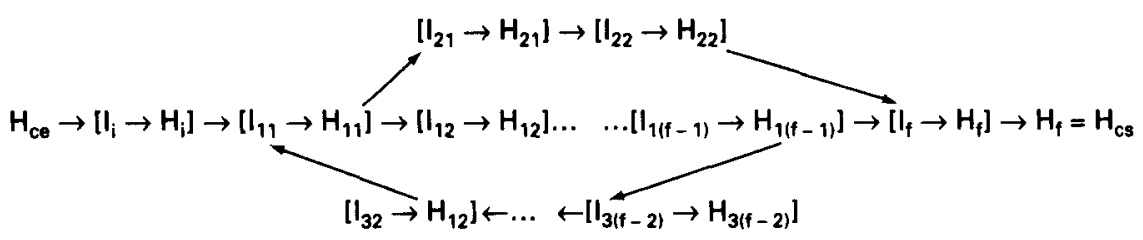

Gráfico 2.

Gráfico 2: Representación de un Entorno-Proceso social.

$\left[\mathbf{I}_{\mathbf{j k}-} \mathbf{H}_{\mathbf{j k}}\right]$ : cualquier fase $\left(\mathrm{I}^{\wedge} \mathrm{H}\right) \mathrm{S}$ en el Entorno-Proceso; «j», primer subíndice, se refiere a la cadena en que se inscribe el $\left(\mathrm{I}^{\wedge} \mathrm{H}\right) \mathrm{S}$, y «k», el segundo, la fase dentro de la cadena.

«i» y $<$ f» : subíndices que indican la fase inicial y final.

«ce» : subíndice de la «cola de entrada»: $\mathbf{H}_{\mathrm{ce}}$ es resultado de un Entorno-Proceso precedente al actual en curso.

«cs» : subíndice de la «cola de salida»: $\mathbf{H}_{c s}$ es el resultado del proceso actual, equivale a $\mathbf{H}_{r}$

Segundo, el Entorno-Proceso está delimitado situacional, agencial y espacial y temporalmente aunque influyan contextos externos. Dicha delimitación es particularmente importante en el ARS. Desde mi punto de vista la frontera del Entorno-Proceso está dada por tres criterios básicos. En primer lugar, la invariabilidad de los agentes o artefactos considerados como agentes en el proceso. Se parte de que los agentes son mecanismos de transformación y que, por tanto, pueden modificar, de manera más o menos importante por su relativo grado de autonomía, la realidad que se transforma en el proceso. En segundo lugar, la existencia de una unidad espacio-comunicativa del proceso que puede ser incluso virtual. En tercer lugar, un grado suficiente, aunque sea relativo, de identidad, autonomía y estabilidad del resultado de la interacción como hecho o producto.

Tercero, el Entorno-Proceso se lleva a cabo en los contextos y campos con los que interactúa.

Cuarto, el Entorno-Proceso aboca a la modificación material o simbólica de un producto. Eso es, confluye hacia un resultado o hecho con un «valor» añadido (se volverá sobre ello) o identidad, material y cognitiva o, en términos de la Cognición socialmente distribuida, representación social externa o interna. Dicha plusvalía (el producto y su identidad como resultado) se distribuye y es apropiado, equitativamente o no, entre y por los agentes internos o contextuales al Entorno-Proceso; dicho reparto o (re)distribución igual/desigual es decisivo para establecer la diferenciación social, es decir, los grupos o clases y, en consecuencia, la estructura socialmente diferenciada. Veamos los dos primeros aspectos que tienen que ver con los contenidos y fronteras del Entorno-Proceso; los otros dos serán tratados posteriormente. 
Sea una lección impartida en clase, que suponemos interactiva, vertical (profesor-alumnos) y horizontalmente (entre alumnos). Primero, dicha clase, es decir, todo lo que hay y sucede en su desarrollo, que será considerada como un Entorno-Proceso social, no se reduce a un solo doblete Interacción-Hecho social, (INH)S, sino que, en dicha clase y en su desarrollo, pueden darse diversos, verticales $u$ horizontales, uni y bidireccionales. La articulación entre ellos puede ser lineal, en paralelo, en grupos reducidos, en bucles... El conjunto forma una secuenciación de (INH)S y una arquitectura interactiva, es decir, un Entorno-Proceso. Evidentemente hay recursos externos e internos, agentes, artefactos más o menos «inteligentes» y, suponemos, un buen resultado cognitivo (en tanto que representación externa e interna) o de otro tipo que se producen en el proceso. Segundo, se dan los tres criterios de delimitación anunciados: hay una unidad espacio-comunicativa indudable, una 'permanencia' de agentes y artefactos en el proceso y, por fin, un grado de identidad suficientemente estabilizada en los resultados como para poder establecer el final del proceso Entorno-Proceso y, como tal, la frontera de tal unidad de referencia: se supone que la clase está en una dinámica de evaluación continuada con lo que hay un resultado cognitivo como representación interna en los agentes y otros externos como la evaluación incluso con una nota de todo el proceso de la clase (intervenciones de alumnos, evaluación del profesor, resultados por un test o preguntas rápidas de comprensión al final de la clase, apuntes de los alumnos, relaciones cognitivas nuevas entre ellos y con el profesor, etc.). El resultado, además, será apropiado por los agentes. Evidentemente, este resultado es "cola de entrada" para el siguiente Entorno-Proceso pe.de la siguiente clase de la misma asignatura.

¿Qué tiene que ver todo ello con el ARS?. Aunque la pregunta generatriz de una red social sea idéntica para todos los agentes encuestados y se aparente con ella una imagen de homogeneidad situacional, cada vínculo o relación entre dos agentes-nodos, puede provenir de situaciones y/o Entorno-Procesos diferentes, no sólo para cada agente con respecto a otro (en relaciones dirigidas) sino para cada uno de los agentes (en simétrica o no dirigida) al responder separadamente. No hay razón para pesar que los Entorno-Procesos tienen que ser equivalentes, o comparables las situaciones, que además pueden ser "perfectamente» desconocidas en sus contenidos y delimitaciones por el investigador y/o no tener acceso directo a ellas. Una pregunta generatriz de una Red a los alumnos en una clase sobre las relaciones en dicha sesion marca una situación relativamente equivalente de referencia para todos, no así, si en la misma clase, se pregunta acerca de las relaciones de cada alumno en un fin de semana.

Veamos unas orientaciones en cascada, de mayor a menor grado como solución aceptable y/o de compromiso. Primero, si los métodos naturalístico-etnográficos lo permiten, lo óptimo será captar y recoger las Interacciones sociales y/o Relaciones Sociales «en vivo» del conjunto del Entorno-Proceso. Si, además, la temporalidad de la interacción nos posibilita también recoger los resultados reticulares en su relativa clausura, «miel sobre hojuelas». Si no se da tal posibilidad, ya que se difumina o extiende el Entorno-Proceso quedando sin un adecuado cie- 
rre, lo que es un signo de indeterminación en la elección de la unidad de análisis, conviene entonces, si se persiste, tener algún supuesto o inferencia sobre el resultado. Segundo, si no es posible tal aproximación en vivo a los dobletes Interacción-Hecho pero sí a los resultados del Entorno-Proceso, la exigencia es de indagar algo o tener supuestos aceptables sobre las condiciones o situación de interacción en que se dieron dichos vínculos. De todas formas la entrevista nos acerca mejor que la encuesta, por su naturaleza narrativa, a los posibles EntornoProcesos situacionales que pueden producir dichos vínculos como resultado.

Contra lo que pueda parecer, la sensación de homogeneidad y unicidad situacional que puede dar una misma pregunta generatriz a todo un colectivo sobre sus relaciones binarias puede ser engañosa: una pregunta sobre los vínculos entre 40 sujetos de una clase pe. de «prestación de apoyo emocional» entre ellos pudiera tener $40 \times 39$ condiciones o referencias situacionales diferentes. ¿Significa lo mismo en todas ellas el «apoyo emocional»?. Algo más se habrá de conocer de aquel colectivo y sus situaciones emocionales, esto es, de los Entorno-Procesos correspondientes para mejor interpretar los resultados como Redes o Relaciones Sociales. ¿O se deberían explicitar más los posibles Entornos-Procesos para lograr más homogeneidad referencial de las situaciones de interacción?. Otra cosa sería, como se ha avanzado, si la pregunta generatriz tuviera como referente una situación compartida por todos los que participan en la encuesta/entrevista.

\section{LOS CONTEXTOS SOCIALES, LAS RS Y EL ARS.}

La preocupación contextualista en el tratamiento de lo microsocial ha estado presente en muchas teorías sociológicas con más o menos intensidad ${ }^{10}$. Para los

${ }^{10}$ Por ejemplo, la de inspiración interaccionista (Goffman 1963, 1967, 1974) a partir de entornos o escenarios inmediatos dentro de marcos institucionales; la etnometodológica (Cicourel 1964, 1973, 1974, Cicourel y Kitsuse 1963, Cicourel y alt. 1974, Garfinkel 1967, 1986, Garfinkel y Sacks 1970 ) interesada en los modos con que los miembros de una sociedad construyen los acontecimientos en los que participan; Cicourel $(1990,1994,2003)$ va en una dirección más objetivadamente contextualista; la teoría de la acción de Vygotsky $(1978,1986)$ centrada en la mediación de los artefactos, (Engeström 1991, 1995, 1996, Engeström y Middleton 1996, Engestrom, Miettinen y Punamaki 1999); la aproximación etnográfica de la comunicación que vincula el acontecimiento lingüístico al contexto de su situación, (Malinowski 1923, Hymes 1964,1972, Gumperz 1982a, 1982b, Duranti 1988, Duranti y Goodwin 1992); la teoría de las organizaciones en que el contexto o estructura de la organización se equipara a sistemas formales de roles, normas, reglas...(Tosi, Rizzo y Carroll 1995); Fitzpatrick basándose en la Grouded Theory introduce conceptos tales como mundo social y marco local equivalentes a contexto y situación (Fitzpatrick 1998, Fitzpatrick, Mansfield y Kaplan 1996); Mantovani (1996a,b) establece su arquitectura social en tres niveles; el modelo de Layder (1994) de base interaccionista reconoce las estructuras contextuales en dos de sus cuatro niveles, el contexto y el marco o escenario; la Cognición Socialmente Distribuida (Hutchins 1995 a.b., Lozares 2000, 2001, Lozares, Verd, Moreno, Barranco, Masso 2004, Kirsh 2001, Cicourel 1994, 2003) toma como unidad de referencia de análisis el conjunto de agentes, humanos y artefactos, y las interacciones del entorno situacional (Hutchins y Klausen 1996, Pea 1993) y considera los contextos sociales y culturales como actuantes aunque no estén tan presentes en sus análisis. 
propósitos actuales consideramos los siguientes niveles dentro de esta arquitectura expansiva de lo social basada en el Entorno-Proceso como unidad de referencia y análisis.

La idea de Contexto social, se asimila a las entidades sociales en la que se incluyen o inserta (y con la que mantienen influencias e interacciones mutuas) el Entorno-Proceso social y situacional. Tomando el lenguaje de Layder consideramos dos tipos de Contextos Sociales. El primero, es el Contexto Sustantivo, que se refiere a entidades, agentes, instituciones, organizaciones, grupos sociales,...que engloban y contienen más inmediatamente el ( $\left.\mathrm{E}^{\wedge} \mathrm{P}\right) \mathrm{S}$ situacional. El segundo tipo, es el Contexto Formal, que es de carácter más abstracto y genérico. Está constituido por categorías, clases, formaciones sociales que establecen, a partir de dimensiones o factores fundamentales de discriminación y/o diferenciación social, posiciones claves y determinantes en la estructura social y en la explicación social global de la misma. Son transversales a los Contextos sustantivos y de carácter macro-social y son objeto directo del estudio de la estructura social: las clases y formaciones socioculturales; género; ámbitos de administración política, país, estado, región...Se entiende que los Contextos no son simples escenarios estructurales que modifican con su solo poder escenográfico los «procesos-entornos situacionales» sino que son entidades agenciales que intervienen más o menos directamente sobre ellos, y viceversa. La delimitación entre Entorno-Proceso y sus Contextos no está cerrada a cal y canto y puede ser borrosa y homeostática.

¿Y qué pasa en el ARS? En el ARS no hay una preocupación específica ni menos inquietante por tales precisiones o contorneos socio-temporales; no la hay por delimitar y definir situacionalmente los Entorno-Procesos para que sean las unidades de referencia del análisis pero tampoco por enmarcarlos y circunscribirlos en el tiempo y en sus contextos. ¿El divino halo holista un tanto internalista - la Red es su propio contexto- que envuelve el ARS le impide otros halos contextuales más amplios? ${ }^{11}$. La preocupación por la contextualización de los Entorno-Procesos, donde se dan las situaciones de interacción que generan las Redes Sociales, tiene la doble ventaja de dar mayor significado a sus contenidos y propiedades y de facilitar la comparación con las Redes Sociales de otros contextos.

Es un ejercicio poderosamente informativo y contextualizador que, en el análisis de redes de un Entorno-Proceso concreto (pe. entre agentes/instrumentos del proceso de tinte en un taller de una empresa textil), primero, se extienda dicho análisis a la Red Social más amplia de todos los agentes/instrumentos del taller o empresa; segundo, que se lleven a cabo ARS entre agentes/instrumentos situados en diferentes niveles de contextualización de los que depende y con los que interacciona el proceso Entorno-Proceso de tinte (pe. entre cuadros, jefes, encargados, tintoreros de otras empresas,...e instrumentos). Ello sin 'salir del

${ }^{1}$ Quizás los «reticulistas» tengan una obnubilación semejante a la que los «atributistas» tienen cuando bajan del monte de las «tablas» de la ley de las Variables y del Análisis de Datos. 
paradigma reticular, que no es la única manera de identificar y analizar contextos en el ARS.

\section{LOS CAMPOS, VALORES, CAPITALES, CVC, LAS RS Y EL ARS}

Además de los Contextos en los que se «sitúan» los Entorno-Procesos situacionales sociales, éstos se «inscriben» y dinamizan en Campos, Valores y Capitales sociales. Sólo entro en la especificidad de contenidos y tipos dados aquí a dichos términos, (Arsant 1990, Bourdieu 1980, 1981, 1983, 1986, 1992, Lozares 2003). Se emplea el concepto de Valor para señalar que se trata de una identidad que proviene del (o es buscada como) resultado plusvaluado del Entorno-Proceso dentro de una cierta homogeneidad social más amplia. Con el concepto de Campo me refiero a la dinámica del proceso de la creación del Valor al considerar que el (o conjuntos de) Entorno-Procesos, con un cierto grado de homogeneidad social, se sitúan y están inmersos en espacios, tiempos, lógicas, estrategias, relaciones, «correlaciones de fuerzas»,... que los modifican, refuerzan o neutralizan; a su vez, los cambio de los Entorno-Proceso modifican las condiciones del Campo. Así se puede hablar del Campo educativo, artístico, salud,... El Capital es el Valor en cuanto apropiado por agentes, una especie de «energía potencial» apropiada en forma de recursos, estatus, posición y poder que se transforma en estructura y orden social. En resumen, de los tres CVC, el Campo representa, cual «campo de fuerzas», la componente dinámica y cambio; el Valor, la identidad sustantiva y plusvaluada; y, el Capital, los recursos diferenciales en forma de grupos, estructura y poder a partir de la apropiación del Valor.

El supuesto que hago es que tres CVC, como son el de Uso/Funcional, el de Cambio/Económico y de Signo/Cognitivo, forman base y que, considerados en pertinencia social, están al origen, dinamizan y configuran todas las posibles identidades sociales ${ }^{12}$. Esto es, las identidades sociales que son infinitas provienen de las infinitas combinaciones posibles, no necesariamente lineales, de dichos tres CVC vistos en pertinencia social. Es indiscutible el peso que (socialmente) juegan cada uno y los tres: marcan identidades importantes en la vida social, dinamizan procesos y estructuran legitimidad, recursos y poder. Desarrollo muy sucintamente los CVC Signo/Cognitivo; los de Uso/Funcional y Cambio/Económico son más recurridos y asimilables a su sentido en la concepción marxista.

El CVC Signo o Cognitivo proviene de que conjuntos de Entorno-Procesos situacionales se articulan entre sí y sus contextos constituyendo una reticulación significante de tal forma que dada la dimensión o componente cognitiva inhe-

${ }^{12}$ En dichos CVC sociales pueden definirse unos atributos intrínsecos. Se trata de (i) una dinámica propia de la interacción bajo el dominio del Campo, (ii) una identidad social fundamental o Valor propio fundamental de Uso/Funcional, Cambio/Económico y Signo/Cogntivo; (ii) una estática en cuanto que se estructuran y ordenan en Capital y, con ello, una medición o «métrica». 
rente a todo $\left(\mathrm{I}^{\wedge} \mathrm{H}\right) \mathrm{S}$, y por ende a los conjuntos de Entorno-Procesos, se constituye un sistema que además de interactivo es cognitivo. El Valor Signo/Cognitivo es el conjunto de representaciones (u otros procesos cognitivos) externas e internas de dicho sistema. Los agentes que dominan este Campo Signo/Cognitivo son los que con más probabilidad se apropian de los beneficios cognitivos que provienen de los Entorno-Procesos en el Campo en cuestión. Los Valores Signo/Cognitivos apropiados o apropiables consisten de los 'nombres' de las cosas, de los acontecimientos, actividades, interacciones, bienes, sujetos, instrumentos, instituciones, etc. y que extensivamente constituye le Campo cultural. El poder cognitivo se deriva de la posesión, posición o estatus de los agentes de y en el Capital cognitivo: son recursos o Valores que dan estatus, posición y capacidad o poder de «dar los nombres», es decir, significado y sentido a la realidad. La manipulación y el uso del Capital Signo/Cognitivo para Sí o Nosotros contra Otros constituye la violencia simbólica.

La pregunta oportuna es ¿cómo se generan los CVC sociales o de dónde le viene la pertinencia social a los CVC mencionados o a sus combinaciones?. El Valor social consiste en un bien, beneficio, plusvalía o identidad que cada, o un conjunto de Entorno-Proceso produce en cada uno de los CVC considerados (o sus combinaciones) de tal manera que su apropiación por los agentes establece, como resultado, ligámenes o vínculos, identidades, recursos, etc. entre ellos. A partir de dichas apropiaciones y vinculaciones se generan los Yo(es)/Self cara al Resto de Agentes y/o los Nosotros cara a los Otros. Es decir, se producen identidades sociales. Dicha identidad o pertinencia social se «transmite», en consecuencia, a todo lo que está implicado en los Entorno-Procesos y sus conjuntos: define socialmente a los sujetos, a los objetos y recursos, los resultados y las representaciones, etc. Por ello los CVC de Uso o Funcional, de Cambio o Económico y de Signo o Cognitivo y sus combinaciones son sociales. El Valor social apropiado, que se transforma en recurso de todo tipo, estatus y posición y poder en agentes o grupos, es la Capital social; su desigual distribución establece la diferenciación, la estructura, el orden y el poder social.

¿Qué quiere decir todo esto desde la perspectiva del ARS?. Los CVC sociales considerados como básicos y sus combinaciones generan infinidad de $\mathrm{Re}$ des o relaciones Sociales ${ }^{13}$, por tanto unas fundamentales pe. de uso/funcional

${ }^{13}$ Los diversos CVC sociales y sus combinaciones dan pie a infinidad de Redes Sociales (y clasificaciones) como por ejemplo: (i) Las relaciones territoriales: defensa y conquista de la geografía, de los recursos territoriales como el espacio, la posición geopolítica, las riquezas naturales, humanas, técnicas, culturales, económicas y potencia militar; las colectividades correspondientes son las hordas, tribus, clanes, ciudades, pueblos, naciones, imperios. (ii) El campo de las relaciones de clase o de dominación pe. de edad, lengua, clan, etnia, religión, opinión filosófica, habitat o grupos de clase y/o presión (actores colectivos más o menos estructurados que expresan o defienden sus intereses). (iii) Las relaciones institucionales: conjunto de relaciones cuyo objeto consiste en la gestión de las relaciones entre la defensa de los intereses y el respeto de los compromisos entre grupos de presión. (iv) Las relaciones organizativas: es el marco intersocial, (de clase, institucional y político) donde toda colectividad humana organiza su vida cotidiana que permite reproducir, socializar a sus miembros, producir e intercambiar bienes y servicios, defenderse y ata- 
(apoyo, ayuda,.), de cambio/económico o signo/cognitivo y otras derivadas de ellas con ponderaciones no necesariamente lineales pe. las artísticas, educativas...

En el campo de la compra en supermercado u otro comercio, las interacciones o transacciones básicas parecen situarse exclusivamente en el CVC socio-económico. Pero en realidad, es una combinación ponderada de transacciones de los CVC de usolfuncional (consumo y necesidades familiares, individuales, comprar para una amiga, ir a pasar el rato, comprar algo..); cambioleconómico (hegemónico en el caso) y signo/cognitivo y cultural (información, prestigio de productos, propaganda, etc.). Su combinación en situación configura el CVC social de la compra en supermercado. Las Redes Sociales generadas en dicha situación consistirán también en una combinación de las redes de los tres CVC. Ídem en otros CVC y Redes Sociales como pe. educación, arte, investigación.

Vistas las Redes Sociales desde esta perspectiva, la toma en consideración de los diferentes CVC, desprende y conlleva un potencial clasificatorio importante para el ARS además de las contribuciones básicas referentes a la dinámica, correlación de fuerzas, presencia y generación de interacciones y redes sociales, en lo que no entramos. En la literatura del ARS se dan varias clasificaciones de las Redes Sociales (apoyo, afinidad, información...) con riesgos de superposición semántica. Los tres CVC sociales que forman base y que operan con sus lógicas específicas, ofrecen un buen criterio matricial de clasificación básica de las Redes Sociales: las Redes de uso o de utilidad funcional con su propia lógica, (pe. sostén, apoyo, prestación, hacer con, usar o utilizar con, útil o sirve para, ayudar a, etc.,...); las económicas (prestar a, deber a, comprar a o en, negocio con, denuncia a, OPA amistosas y hostil, personal o bancaria sobre, etc...) y las cognitivo-culturales (conocer, confianza, comunicar, informar, resolver problemas, representar, disponer de, juzgar o valorar a, estimar a,...). La forma de articulación de los CVC y de las Redes Sociales admite muchas formas de composición: el CVC y RS uso/funcional puede ser pe. la «materia prima» significante para un significado de cambio/económico y, ambos, con respecto al CVC o RS signo/cognitivo. La realidad reticular tiene así un cierto grado de complejidad al recoger la riqueza de los contenidos que componen la variedad social de los CVC diversos.

car, movilizar sus actores colectivos, informarse , innovar, administrar su territorio y sus recursos. (v) El campo de las relaciones políticas o la capacidad de una fuerza política de apropiarse de las prerrogativas del estado (legislar, juzgar, reprimir y gobernar) en las relaciones con otras fuerzas políticas, (ver Bajoit 1992). Pero se dan otros CVC sociales combinaciones de los tres básicos (uso/funcional, cambio/económico, cognitivo/culturales en cuanto sociales): pe. el campo artístico, el de judicatura, el de la enseñanza, el de la ciencia-investigación, el del deporte-espectáculo, el del mercado laboral... 


\section{LOS MODOS DE VÍNCULOS SOCIALES Y, POR TANTO, DE LAS RS}

Como hemos visto los CVC sociales (y las Redes Sociales) actúan sobre (y son el resultado) de (o conjuntos de) Entorno-Procesos situacionales inscritos en la dinámica y la estructura de los Campos y Contextos. Denominamos Modos de Redes Sociales a las formas o tipos básicos de vinculación cristalizada que se dan entre los diferentes sujetos o agentes sociales que intervienen en los Entorno-Procesos situacionales y en las Redes Sociales. Concretamente, se trata de las formas de los vínculos que se dan entre los Self y el Resto de agentes, del Nosotros cara a los Otros en su dinámica por la desigual o igual distribución de la «plusvalía» social. Hay dos modos o formas básicos: uno «entre o inter» los sujetos o actores, es el de Intercambio, y otro «dentro o intra» los sujetos o actores, es el de Solidaridad. Lo que lleva a diferenciar dos modos de vínculos básicos en las Redes Sociales y, en consecuencia, a poder formas de clasificación de las mismas.

Los Modos de relaciones de Intercambio son los producidos por procesos de diferenciación-integración. Bajoit (1992) distingue cuatro: los de complementaridad entre agentes con roles diferenciados; los competitivos entre sujetos o grupos en concurrencia por un bien; los conflictivos; y los contradictorios por las que los sujetos sociales tienden a «eliminarse» recíprocamente.

Los modos de relaciones de Solidaridad son los producidos por procesos que llevan a relaciones e identidades de equivalencia (similaridad, semejanza, igualdad, etc.) entre los sujetos (individuos, entidades, grupos, etc). Este modo genera identidades sociales básicas dentro del Yo y/o del Nosotros sociales como dentro de los Otros. Bajoit (1992) establece una tipología basándose en la solidaridad de Tönnies (lazos comunitarios-reconcientos comunes- y societalescomplementaridad de intereses) y de Durkheim (solidaridad mecánica y orgánica) : la solidaridad funcional se refiere al lazo orgánico de Durkheim: el grupo está integrado por roles diferenciados y complementarios que organizan la división social del trabajo, p.e. las organizaciones; la solidaridad contractual que consiste en el lazo societario de Tönnies o el contrato social de Rousseau: el interés de cada uno tiene necesidad de los otros lo que implica un pacto de asociación, no de sumisión; la solidaridad serial de Sartre: la integración en el grupo se hace por la sumisión de sus miembros a una autoridad, poder (estado, partido, jefe); la solidaridad fusional de Sartre: cada uno se funde en la comunidad como unidad basada en la praxis y desde luego no en la yuxtaposición de parecidos.

No es habitual que se recurra a estos Modos de vínculos o de relacione sociales en el ARS, tan corrientes sin embargo en otras disciplinas o teorías. Y sin embargo, parece importante que el ARS se los plantee, sea como aproximación teórica y conceptual o como operativa y empírica, o ambas a la vez, a partir de preguntas u observaciones generatrices de Redes Sociales que expresen estrategias o vínculos de intercambio (complementarias, conflictivas, competitivas o 
contradictorias) o de solidaridad (funcionales, contractuales, seriales y en fusión o expresivas). Tales Modos de Redes Sociales provienen de las dinámicas, recursos, estrategias y resultados propios a los $\left(\mathrm{I}^{\wedge} \mathrm{H}\right) \mathrm{S}$ y los Entorno-Procesos y la inscripción e interdependencia que mantienen con los Contextos y Campos. Una buena parte de las preguntas generatrices al uso en la Redes Sociales están sobre todo orientadas o tienen que ver más con diversos Modos colaborativos con marcados tildes de Solidaridad, (apoyo, consejo, sostén, convivencia, colaboración, prestación, amistad, conocimientos) y que, dentro de las de Intercambio, aparecen únicamente las de complementaridad dándose por desaparecidas las competitivas, conflictivas o contradictorias. De todas formas, lo importante es tener en cuenta, primero, los aspectos situacionales y contextuales que son los que dan información sobre los modos de interacciones, relaciones y Redes Sociales y, segundo, que las distinciones precedentes pueden ser otro buen criterio de clasificación de las Redes sociales.

\section{REFLEXIONES FINALES}

1. Uno de los objetivos iniciales del artículo ha consistido en ofrecer algunas reflexiones para fundamentar más sociológica y metodológicamente el ARS. La utilización casi pragmatista y a veces algo irreflexiva del ARS como una maquinaria para procurar y tratar datos reticulares y la naturaleza multi o interdisciplinar, un tanto neutralizadora de contenidos, puede llevar a la aplicación del análisis sin rodearse de las precauciones metodológicas acerca de la obtención y validación ecológica de los datos y sin delimitar claramente el objeto de estudio, el Entorno-Proceso como foco central, los Contextos y Campos en los que se inscribe y las dualidades que constituyen o son inherentes a cualquier relación e interacción social.

He tratado de situar la problemática en la raíz desde la que, según mi punto de vista, se engendra todo lo social, esto es, la Interacción Social en su despliegue y complejidad, procurando incrustar en ella la idea de relación y Red Social. Así recibe, desde su misma génesis, una marca y denotación directamente social y una metodología respetuosa de su contenido. La naturaleza social de las Redes Sociales ha quedado confirmada sucesivamente al identificar, delimitar y profundizar la unidad elemental de lo social como es el doblete dual $\left(\mathrm{I}^{\wedge} \mathrm{H}\right) \mathrm{S}$ y la unidad de referencia de análisis como es Entorno-Proceso social y situacional. En ellos las Redes Sociales adquieren una clara plenitud, coherencia, dinámica o estabilidad sociales encuadrando además la Redes en los marcos básicos de determinismos y/o «facilidades sociales» como son los vínculos temporales, espaciales, objetuales, relacionales contextuales y campales.

Idéntico propósito de identificación social se persigue, pero en una perspectiva más macrosocial, a partir de la inserción de las los dobletes $\left(\mathrm{I}^{\wedge} \mathrm{H}\right) \mathrm{S}$, los Entorno-Procesos y consecuentemente también las Redes Sociales, en los Contextos y en los Campos, Valores y Capitales sociales con sus dinámicas específicas. 
2. Estas reflexiones han servido también para caracterizar y clasificar las RS desde diferentes puntos de vista y sobre todo desde su complejidad: (i) desde la naturaleza dual de doblete $\left(\mathrm{I}^{\wedge} \mathrm{H}\right) \mathrm{S}$ y los Entorno-Procesos como realidades dinámicas y en construcción o como estabilizadas o hechos/resultados y/o como Redes cognitivo-subjetivas o Redes fácticas; (ii) como Redes consideradas en una temporalidad definida o como «instantáneas"; (iii) como Redes delimitadas a una sola interacción o consideradas como un compuesto más o menos modular de interacciones; (iv) como Redes «clausuradas y aisladas» en su Entorno-Poceso situacional o abiertas a sus Contextos; (v) como Redes específicas de un Campo-Valor-Capital social base (Uso/Funcional, Cambio/Económico y de Signo/Cognitivo) o como combinación de ellos pe., en Redes Sociales territoriales, de clase y dominación, institucionales organizativas, políticas, artísticas, educativas, científicas, laborales, etc. (vi) tipos de redes según los Modos o formas de relación como son las de intercambio y solidaridad y sus modalidades respectivas dependiendo de las finalidades u objetivos de la intervención y los modos de control de los agentes sociales.

3. De particular interés han sido los corolarios de tipo metodológico que han ido jalonado y poblando estas reflexiones. Vistos en general se pueden resumir a partir del respeto, primero, de la naturaleza situacional y naturalista de la recogida de información y datos y, más genéricamente, de su validación socio-ecológica y contextual; segundo, de las exigencias duales de la construcción del objeto, exigencias que muchas veces se presentan imposibles pero que pueden subsanarse parcialmente con algunas precauciones. Todo ello no suele ser tan tenido en cuenta en el ARS pues al moverse en una especie de rentabilidad inmediata y con resultados tan eficaces y además realísticamente visibles e (imagen)nativos parece que huelga cualquier reflexión metodológica que arrope su construcción y validación: «todo está ahí, basta verlo».

4. Precedentemente, recogía la idea de que el ARS como teoría y método no es, desde mi punto de vista, ni holista ni atomista sino relacionista, ni exclusivamente macrosocial ni microsocial también es mesosocial, ni sólo estructural ni interaccional es también su mutua dualidad, ni sólo realista ni sólo cognitiva, es su génesis mutua y recíproca. Decía que la Redes Sociales, y el ARS, tiene condiciones sustantivas y metodológicas como para ser puente entre riveras de ambos lados y que el marco teórico y epistemológico más pertinente podría ser el del Relacionismo considerándolo como un paradigma que estudia los fenómenos/hechos sociales a través de los procesos constituidos de lazos o relaciones entre sujetos sociales. Parece que toda la exposición redunda esta concepción y, de alguna manera, la confirma. Pero como reflexión más general, aunque aquí solamente apuntada pero susceptible de futuras indagaciones ya en marcha, soy de la opinión que la teoría y el ARS se inscriben en (o es parte de) una gran constelación de teorías cuya denominación o marco general se intuye pero de la que queda mucho por encontrar y bautizar, sobre todo para las ciencias sociales, 
como son las Ciencias de la Complejidad, de la Emergencia, Generativas...que superan las distinciones macro-micro, holista-individuales, etc. Sencillamente forman otra galaxia aún poco explorada por los sociólogos en general por los científicos sociales. 


\section{BIBLIOGRAFIA}

ARSANT, P. (1990): Les sociologies contemporaines. París, Ed. du Seuil.

BAJolT, G. (1992) Pour une sociologie relationnelle. París, PUF.

Blumer, H. (1969): Symbolic Interactionism: Perspectives and Methods. Englwood Clifs, NJ, Prentice-Hall.

Borgatti, S. P., Foster, P. C. (2003): «The Network Paradigm in Organizational Research: A Review and Typology» Journal of Management 2(6): 991-1013.

BouRdiEU, P. (1977): Outline of a Theory of Pratique. Cambridge, Cambridge University Press.

- (1980): Le Sens pratique. París, Minuit.

- (1981): "Champ du pouvoir, champ intellectuel et habitus de classe en Scolies», Cahier de recherche de l'Ecole normale supérieur' 1:7-26.

- (1983): «The Field of Cultural Production or the Economic World Reserved», Poetics 12(4-5): 311-356.

- (1986): «The Forms of Capital», in Richardson J. G., Handbook of Theory and Research for the Sociology of Education. New York-Wesrport, London, Greenwood Press.

- (1992): Reponses. París, Ed. du Seuil.

Carrington, P. J., SCOTT, J., Wasserman, S. (2005): Models and Methods in Social Network Analysis. Cambridge, Cambridge Universty Press.

Cicourel, A. (1990): «The Integration of Distributed Knowledge in Collaborative Medical Diagnosis", in: Galegher, J., Kraut, R. E. and Egido, C. (eds.), Intellectual Teamwork. Social and Technological Foundations of Cooperative Work. Lawrence Erlbaum Associates, pp.: 221-242.

- (1964): Method and Measurement in Sociology. NY, Free Press.

- (1974): Cognitive Sociology: Language and Meaning in Social Interaction. London, Penguin (also New York, Free Press),

- (1994): «La connaissance distribuée dans le diagnostique médical». Sociologie du travail $36(4)$ : $427-448$.

- (2003): «On contextualizing applied linguistic research in the workplace. Joumal of Applied Linguistics (Special Issue edited by Chris. Candlin and Srikant Sarangi), in press.

Crcourel, A. and alt. (1974): Language Use and School Performance. NY, Academic Press.

CicouREL, A. y KITSUSE, J. I. (1963): The Educational Decision makers. NY, Bobbs Merril.

Clark, A. (1996): Being There. MIT Press, Cambridge, MA.

Collins, R. (1987): «Interaction Ritual Chains, Power and Propiety: The Micro-Macro Connection as an Empirically Based Theoretical Problem», in: Alexander J., y alt. (eds). The Micro-Macro Link. Berkeley, University Of California Press, pp. 193-206.

CresPI, F. (1989): Social Action and Power. Oxford, UK, Cambridge, USA, Blackwell.

Cross, R., PARKer, A. (2004): The Hidden Power of Social Networks. Boston, Harvard Business School Press.

DuraNTI, A. (1988): «Intentions, Language and Social Action in a Samoan Context» Journal of Pragmatics, 12:13-33.

DuRANTI, A. GOODWIN, CH. (1992): Thinking context. Cambridge. UK, Cambridge University Press. 
EDMOND, M., DominiQuE, P. (1992): La interacción social. Barcelona, Piados.

EMIRBAYER, M. (1997): «Manifesto for a Relational Sociology», American Journal of Sociology, 103(2):281-317.

ENGESTROM, Y. (1991) «Developmental work research: Reconstructing expertise through expansive learning», in: Nurminen, M., and Weir, G. (eds.), Human Jobs and Computer Interfaces, Elsevier, Amsterdam.

ENGESTRÖM, Y. (1995): «Situated cognition» Artificial Intelligence in Medicine, (7):395412.

- (1996): «Developmental studies of work as a testbench of activity theory: the case of primary care medical practice» en S. Chaiklin, and J. Lave (eds.), Understanding practice: perspectives on activity and context. Cambridge, MA, Cambridge University Press, pp. 64-103.

EngeströM, Y. and Middleton, D. (1996): Eds. Cognition and Communication at Work, Cambridge UK, Cambridge University Press, pp, 296-318.

Engeström, Y., Mietrinen, R. and Punamaki, R. (1999) Perspectives on activity theory. Cambridge, UK, Cambridge University Press.

FITZPATRICK, G. (1998): «The Locales Framework: Understanding and Designing for Cooperative Work», PhD Thesis, in: Dept of Computer Science \& Electrical Engineering, The University of Queensland.

FTTZPATRICK, G., MANSFIELD, T. and KAPLAN, S. (1996): «Locales framework: Exploring foundations for collaboration support", in: J. Grundy and M. Apperley, (eds), Proceedings Sixth Australian Conference on Computer-Human Interaction, IEEE Computer Society Press, pp. 34-41.

GalaskieWITCZ, J., WasSERMAN, S. (1993): «Social Network Analysis. Concepts, Methodology, and Directions for the 1990s», in: Sociological Methods \& Research 22 (1):3-22.

GARFINKEL, H. (1967): Studies in Ethnometodology. Englewood Cliffs, Prentice-Hall.

- (1986): (Ed.) Ethnomethodological studies of work. London, Routledge.

GARFINKEL, H., SACKS, H. (1970): «On Formal Structures of Practical Actions», in: McKinney, J. D. and Tiryakian, E. A. Theoretical Sociology. NY, Appleton-CenturyCrofts, pp. 337-366.

GiDdENS, A. (1984): The Constitution of Society: Outline of the Theory of Structuration. Cambridge, Polity Press.

GofFMan, E. (1963): Behaviour en Public Places: Notes on the Social Organization of Gatherings. NY, Free Press.

- (1967): Interaction Ritual: Essays on Face-to face Behavior. Garden City. NY, Anchor/Doubleday.

- (1971): The Presentation of Self in Everyday Life. Harmondsworth, Penguin.

- (1974): Frame Analysis: An essay on the Organization of Experience. NY, Harper and Row.

GranovetTeR, M. (1973): «The Strengh of Weak Ties», American Jounal of Sociology, 78.

GuMPERZ, J. J. (1982a): Discourse Strategie. Cambrige, Cambrige University Press.

- (1982b): Language and Social Identity. Cambidge, Cambrige University Press.

HABERMAS, J. (1984): The Theory of Communication Action, V.I: Reason and the Rationalization of Society. Boston, Beacon Press.

Hollis, M. (1998): Filosofía de las ciencias sociales. Barcelona, Ariel.

HoMANS, G. (1974): Social Behavior: Its Elmentary Forms. NY, Harcourt, Brace. 
HuTchins, E. (1995a): «How a cockpit remembers its speeds». Cognitive Science 19:265288.

- (1995b): Cognition in the wild. Cambridge, MA, MIT Press.

HUTCHINS, E. and KLAUSEN, T. (1996): «Distributed cognition in an airline cockpit», in: Y. Engestrom, H. and D. Middleton (eds.), Cognition and communication at work. New York, Cambridge University Press, pp. 15-34.

HYMES, D. (1964): Language in Culture and Society. NY, Harper and Row.

- (1972): «Models of the Interaction of Language and Social Life», in: Gumperz, J. J. and Hymes, D. (eds.), Directions in Sociolinguistics: The Ethnography of Communication . NY, Holt, Rinehart and Winston, pp. 35-71.

HYMES, D., GUMPERZ, J. J. (1972): «Models of the Interaction of Language and Social Life», in: Gumperz, J., Hymes, D. (eds.), Directions in Sociolinguistics: The Ethnography of Communication . NY, Holt, Rinehart and Winston, pp. 35-71.

KIRSH, D. (2001): «The Context of Work», Human Computer Interaction, 16:31.

KNOKE, D., KuKLINSKI, J. H. (1982): Network analysis. Newbury Park, London, Sage.

LAMO DE ESPINOSA, E. (1990): La sociedad reflexiva. Madrid, CIS.

LAYDER, D. (1981): Structure, Interaction and Social Theory. London [Etc.], Routledge \& Kegan Paul Limited.

- (1994): Understanding Social Theory. London, Thousanh Oaks. Sage Publications.

LEMIEUX, V. (1999): Les réseaux d' acteurs sociaux. París, PUF.

LOFLAND, J. (1978): Interaction in everyday life. Social Strategies. Beverly Hills/ London, Sage Publications.

LOZARES, C. (1996): «La teoría de redes sociales», Papers, 48.

- (2000): «El discurs reticular; més enllá de la classificación, Revista Catalana de Sociología 11:183-191.

- (2001): «La actividad situada y/o el conocimiento socialmente distribuido», Papers, 62:97-131.

- (2003a): «Reflexiones metodológicas y sociales a partir del "mundo pequeño" de Milgram", Araucaria. Revista lberoamericana de Filosofia, Política y Humanidades 5(10):48-68.

- (2003b): «Valores, campos y capitales sociales». Revista hispana para el análisis de redes sociales. ISSN 157 9-0189. (Revista electrónica) www.redes-sociales.net, Vol. 4.

LozARES, C., VerD, J. M., MARTi, J., LOPEZ, P., (2003): «Relaciones, redes y discurso: revision y propuestas en torno al análisis reticular de datos textuales». REIS 101:175200.

- (1998): «El tratamiento multiestratégico en la investigación sociológica», Papers 55:27-43.

- (2001): «Relaciones, redes y discurso: revisión y propuestas en torno al análisis reticular de datos textuales», REDES, Revista hispana para el análisis de redes sociales. ISSN 157 9-0189. (Revista electrónica) www.redes-sociales.net, Vol. 1.

Lozares, C., Verd, M., Moreno, S., Barranco, O., Masso, M. (2004): «El proceso de trabajo desde las perspectivas de la actividad situada y del conocimiento socialmente distribuido", Cuadernos de relaciones laborales. 22(1):67-87.

MALINOWSKI, B. (1923): «The Problem of Meaning in Primitive languages», in: Ogden C. K., Richard I. A. The meaning of Meaning. NY, Harcourt, Brace and World, pp. 296336.

ManTovani, G. (1996a): New communication environments: From everyday to virtual. London, Taylor \& Francis. 
- (1996b): «Social Context in HCI: A New Framework for Mental Models, Cooperation, and Communication», Cognitive Science 20:237-269.

MEAD, G. H. (1934): Mind, self, and society. Chicago, The University of Chicago Press.

- (1938): The Philosopy of the Act. Chicago, The University of Chicago Press.

MerCKLÉ, P. (2004): Sociologie des réseaux sociaux. París, La Decouverte.

Molina, J. L. (2001): El análisis de redes sociales. Una introducción. Barcelona, Edicions Bellaterra.

NoRmAN, D. A. (1993): Things that make us smart. Addison-Wesley, Reading, MA.

PEA, R. D. (1993): «Practices of distributed intelligence and designs for education», in: G. Salomon (Ed.), Distributed cognitions: psychological and educational processes. Cambridge, MA, Cambridge University Press, pp, 47-87.

REQUENA, F. (1989): «El concepto de red social», REIS 48:137-152.

RITZER, G. (2000): Modern Sociological Theory. Boston, McGraw Hill.

RITZER, R., GINDOFF, P. (1992): «Methodological Relationism: Lesson for and from social psychology», Social Psychology Quartely 55(2):128-140.

SALVADOR JuAN (1995): Les formes élémentaires de la Vie Quotidienne. París, PUF.

SchÜTZ, A., LuCKMAN (1973): The Structures of the Life World. Evanston, North Western University Press.

ScotT, J. (1991): Social Network Analysis. Newbury Park, London, Sage.

- (1998): «Relationism, Cubism, and Reality: Beyond Relativism», in: May, T., Willams, M., Knowing. The Social World. London, Open University Press.

STRUCTURE Versión 4.2. (1991): Referencia del manual. NY, Center for Social Sciences. Columbia University.

Tosn, H. L., RIZzo, J. R. and CARROLL, S. J. (1995): Managing organizational behaviour. Cambridge, MA, Blackwell.

TURNER J. H. (1988): A Theory of Social Interaction. Stanford, Stanford University Press.

VERD, J. M., LOZARES, C. (2000): «La teoría de xarxes socials aplicades a la interpretació d'entrevistes narratives. Una proposta», Revista Catalana de Sociologia, 11:191-182.

VERD, J. M., LOZARES, C., MARTÍ, J., LÓPEZ, P. (2000): «Aplicació de les xarxes socials a l'analisi de la formació invisible en l'empresa». Revista Catalana de Sociologia, 11:87-104.

VERSCHUREN PIET, J. M. (2001): «Holism versus Reductionism in Modern Social Science Research». Quality \& Quantity, 35:389-405.

VYGOTSKY, L. S. (1978): Mind in Society. Cambridge, Mass., Harvard University Press.

- (1986): Thought and language. Cambridge, MA, The MIT Press.

WASSERMAN, S., FAUST, K. (1994): Social Network Analysis. Cambridge, Cambridge University Press.

WATERS, M., (1994): Modern Sociological Tehory. Sage Publications.

Wellman, B. (1983): «Network Analysis: Some Basic Principles», in: Collins, R. Sociological Theory San Francisco, Jossey-Bass.

Wellman, B., BERKOWTTZ, S. D. (Eds.) (1988): Social Structures: A Network Approach, Cambridge, Cambridge University Press.

ZHAN, J, NORMAN, DA. (1994): Representations in distributed cognitive tasks. Cognitive Science 18:87-122. 


\title{
RESUMEN
}

Este artículo contiene una serie de reflexiones sociológicas y metodológicas sobre el ARS que van más allá de lo que acostumbra a tratar la literatura ad hoc del ARS casi centrada exclusivamente en el análisis de datos. Estas reflexiones tratan de derivar orientaciones metodológicas para el ARS a partir, primero, de profundizar en lo que constituye el origen de la pertinencia social y en las condiciones de producción de las Redes Sociales, RS, como son la Interacción social, IS, los Entornos y los Procesos sociales; segundo, de enmarcar las RS en los Contextos y Campos sociales. Se pretende también, en este artículo, ofrecer algunos criterios de clasificación de las RS fundamentados precisamente en la naturaleza de las interacciones, relaciones, contextos y campos.

\section{PALABRAS ClAVE}

Redes sociales, interacción social, proceso, entorno, contextos, campo social.

\begin{abstract}
This paper contains a series of sociological and methodological reflections on the ARS that goes beyond the analysis of data, as there was usual until now. These reflections try to derive the methodological orientations, first of all, by deepening in what constitutes the source of social pertinence and in the conditions of production of Social Networks (for instance, social interaction, social environment and processes); and secondly, by framing the social networks in the social contexts and social fields. This paper also aims to offer some criteria of classification of social networks based on the nature of the interactions, relations, contexts and fields.
\end{abstract}

\section{KEY WORDS}

Social networks, social interaction, process, social environment, contexts, social field. 